\title{
Hyperventilation Restores Autoregulation of Cerebral Blood Flow in Postictal Piglets
}

\author{
PIERRE MONIN, ${ }^{1}$ BARBARA S. STONESTREET, AND WILLIAM OH
}

Brown University Program in Medicine, Department of Pediatrics, Women and Infants' Hospital

of Rhode Island, Providence, Rhode Island 02905

\begin{abstract}
Autoregulation of cerebral blood flow is impaired in the postictal state. This loss of autoregulation may in part be mediated by a rise in perivascular hydrogen ion and carbon dioxide concentration. We hypothesized that hypocarbia with a concomitant reduction in perivascular hydrogen ion and carbon dioxide concentration would restore autoregulation during the postictal state. We studied autoregulation of cerebral blood flow in 13 ventilated, awake 3- to 4-d-old piglets during the postictal state under normocarbic and hypocarbic conditions. During the postictal state, cerebral blood flow was pressure-passive in normocarbic piglets, whereas the relationship between cerebral blood flow and cerebral perfusion pressure was described by a polynomial curve in hypocarbic piglets. Because hypocarbia restores cerebral blood flow autoregulation in postictal newborn piglets, we speculate that the perivascular hydrogen ion and carbon dioxide concentration contribute significantly to the state of cerebral autoregulation in the postictal subject. (Pediatr Res 30: 294-298, 1991)
\end{abstract}

Autoregulation of cerebral blood flow is important in the maintenance of cerebral hemodynamic balance. The relationship between systemic blood pressure and brain blood flow is well established in man and adult and newborn animals (1-5). Many pathologic conditions known to impair autoregulation render cerebral blood flow pressure-passive, increasing the risk of CNS pathology resulting from hemodynamic abnormalities (6-11). In newborn piglets, we have previously shown that a pressurepassive relationship exists between mean arterial blood pressure and cerebral blood flow during seizures and the subsequent postictal state $(12,13)$. Several factors may mediate this loss of autoregulation, including changes in perivascular potassium and hydrogen ion concentrations, intracranial pressure, systemic blood pressure, cerebral oxygenation, and carbon dioxide production (14-18). Because hydrogen ion and carbon dioxide production have previously been observed to increase after seizures, the concomitant rise in cerebral blood flow has been attributed to an increase in the perivascular concentrations of these two elements (19). Because perivascular hydrogen ion and carbon dioxide concentrations are potent vasodilators of the CNS vasculature $(20,21)$, we hypothesized that arterial hypocarbia with a concomitant reduction in perivascular carbon dioxide and hydrogen ion concentrations would correct the impaired cerebral autoregulation previously reported (13). We tested this hypothesis by examining the autoregulation of cerebral blood flow during the postictal state in normocarbic and hypocarbic piglets,

Received April 24, 1990; accepted May 13, 1991.

Reprint requests: Barbara S Stonestreet, MD. Department of Pediatrics, Women \& Infant's Hospital of RI, 101 Dudley Street, Providence, RI 02905-2499.

'Present address: Maternite Universitaire-Service de Medecine Neonatale, 54042 Nancy, France. thereby manipulating the arterial carbon dioxide concentration, potentially modifying perivascular carbon dioxide and hydrogen ion concentrations by a washout phenomenon. In addition, we also examined cerebral metabolic rate for oxygen to rule out tissue hypoxia, inasmuch as a reduction in oxygen availability may serve as a factor mediating the loss of autoregulation (6).

\section{MATERIALS AND METHODS}

Animals. The study was approved by our institutional review board. Thirteen 3- to 4-d-old, farm-bred piglets obtained from a local hog breeder were studied. The weight of the piglets was $1.55 \pm 0.26 \mathrm{~kg}$ in the normocarbic (mean \pm SEM, $n=7$ ) and $1.77 \pm 0.21 \mathrm{~kg}$ in the hypocarbic group $(n=6)$.

Surgical procedures. Two h before the study, catheters were placed under 0.30 nitrous oxide and 0.70 oxygen and local lidocaine $(0.01)$ anesthesia. Polyvinyl catheters were placed into the left ventricle via the left common carotid artery for radionuclide-labeled microsphere injections, into the thoracic aorta for reference blood sample withdrawal and arterial blood gas and oxygen content samples, into the abdominal aorta for blood pressure and heart rate monitoring, into the inferior vena cava for administration of bicuculline and central venous pressure monitoring, and into the sagittal sinus for pressure monitoring and study sampling. Previous work in newborn piglets has shown that the use of a carotid artery for catheterization of the left ventricle does not alter brain blood flow when the radionuclidelabeled microsphere method is used (22). A tracheotomy was also performed to facilitate ventilatory support. After surgery, the animals received $5 \mathrm{~mL}$ of 0.10 dextrose, and all catheters were filled with a heparin solution $\left(10 \mathrm{U} \cdot \mathrm{mL}^{-1}\right)$. The piglets were then placed in a sling in a darkened chamber and permitted a $2-h$ period of recovery from surgery.

Experimental protocol. Two $\mathrm{h}$ after the completion of surgery, the ventilated (Biomedical Devices, Inc., Stamford, CT) animals remained awake or sleeping in the sling during all measurement periods. The ventilator gas mixture was 0.05 carbon dioxide, 0.21 oxygen, and 0.74 nitrogen. The deep rectal temperature was maintained between 38 and $39^{\circ} \mathrm{C}$ throughout the study. Six series of determinations were performed in each animal, including the following measurements: systemic arterial, venous, and superior sagittal sinus pressure; heart rate; arterial blood gases; hematocrit; and arterial and superior sagittal sinus oxygen content values, along with total and regional brain blood flow determinations. The first determination was obtained before the i.v. administration of $1 \mathrm{mg} \cdot \mathrm{kg}^{-1}$ of bicuculline (Sigma Chemical Co., St. Louis, $\mathrm{MO})$ to induce seizures. The second determination was obtained at a time when the seizures had completely stopped by clinical assessment (mean of 31 min into the experiment). This period was considered the postictal state, and this initial postictal determination was used to assess the effect of the postictal state on cerebral blood flow. Although changes in ventilator settings were not made during bicuculline-induced seizures, additional oxygen was provided to maintain normoxia during the seizures. After this second determination, while the piglets were in the postictal state, the ventilator rate was adjusted in seven piglets to maintain 
normocarbia and in six to induce hypocarbia (arterial $\mathrm{CO}_{2}$ tension $=2.67-3.20 \mathrm{kPa}$ ). Both groups had normal arterial $\mathrm{PO}_{2}$ A third measurement was obtained after the adjustment of $\mathrm{PCO}_{2}$ values (mean time $55 \mathrm{~min}$ ); thereafter, hypotension was induced in both groups by phlebotomy to produce graded reductions in systemic arterial blood pressure to test the state of the cerebral autoregulation at the lower end of the curve. The last three sets of postictal determinations were obtained in each group during sustained hypocarbia or normocarbia and graded reductions in systemic arterial blood pressure. During the first three study measurement periods, blood losses due to study sampling were replaced with blood of a similar hematocrit from a young donor piglet. After the final determination, the piglets were killed with a solution of sodium thiamylal $\left(200 \mathrm{mg} \cdot \mathrm{kg}^{-1}\right)$.

An autopsy was performed to ascertain catheter placement and to procure tissues. The brain was weighed and fixed in 0.10 formalin for $6 \mathrm{~d}$. The kidneys and lungs were harvested, weighed, and fixed in formalin until subsequent carbonization.

Methodology. Using previously established techniques (3, 7 , $10,22,23)$, blood flow was determined with microspheres $15 \pm$ $5 \mu \mathrm{m}$ in diameter labeled with one of the following six radionuclides: ${ }^{46} \mathrm{Sc},{ }^{51} \mathrm{Cr},{ }^{57} \mathrm{Co},{ }^{95} \mathrm{Nb},{ }^{103} \mathrm{Ru}$, or ${ }^{113} \mathrm{Sn}$ (New England Nuclear Inc., Boston, MA). Approximately $6 \times 10^{5}$ microspheres, suspended in a 0.10 dextran solution with 0.0001 Tween 80 , were continuously agitated and were injected over $30 \mathrm{~s}$ via the left ventricular catheter, which was then flushed with $2 \mathrm{~mL}$ of $0.9 \mathrm{NaCl}$. A reference blood sample was continuously withdrawn from the thoracic aorta, beginning $10 \mathrm{~s}$ before the microsphere injection and lasting for $120 \mathrm{~s}$ at a constant rate of $1.03 \mathrm{~mL}$. $\mathrm{min}^{-1}(22,24)$. Heart rate and systemic arterial, central venous, and superior sagittal sinus pressures were continuously measured using a Hewlett-Packard transducer (model 12800; Lexington, MA) and recorded on a Hewlett-Packard polygraph (7754 A series).

After $6 \mathrm{~d}$ of fixation, the brain was dissected into the following regions: cerebrum, cerebellum, and brain stem. In each animal, the entire cerebrum was divided into frontal, parieto-temporal, and occipital cortex and caudate nucleus, including the white matter. The total cerebrum was the sum of each of these regions. Similarly, the entire cerebellum was sampled. The brain stem included midbrain, pons, and medulla. Total brain blood flow represented the sum of all regions sampled. In all animals, an identical dissection was done by one investigator. Brain samples were then packed to a $1-\mathrm{cm}$ height in glass counting vials. Carbonized kidney and lungs were also packed to a $1-\mathrm{cm}$ height in glass vials (24). Blood and tissue specimens were counted in a well-type gamma-scintillation spectrometer [Tracor Analytic sample changer (model 1185, Elkgrove Village, IL) interfaced to a multichannel analyzer, 8192 channel series processor (Canberra Industries, Meriden, CT)]. Blood flow data were generated with a Digital PDP 11/34 computer (Digital Equipment, Maynard, MA) that corrected for isotope spillover and decay. Blood flow was determined using the following equation:

Blood flow $=\frac{\text { Tissue } \mathrm{cpm}}{\mathrm{cpm} \text { of reference blood }}$

$\times$ rate of withdrawal of reference blood

All tissues and reference blood samples had sufficient microspheres to assure blood flow accuracy to within \pm 0.05 (23). Paired samples of lungs and kidneys (data not shown) documented the absence of shunting through a ductus arteriosus and errors due to streaming.

Arterial blood gases were determined on a Corning 175 blood gas analyzer (Corning Scientific, Medford, MA) and oxygen contents were determined in duplicate on a Lex- $\mathrm{O}_{2}$ Con (Lexington Instruments, Waltham, MA).

Computations and statistical analysis. Cerebral oxygen delivery $\left(\mathrm{DO}_{2}\right)$, uptake $\left(\mathrm{V}_{2}\right)$ and oxygen extraction $\left(\mathrm{O}_{2} \mathrm{Ex}\right)$ were calculated from measured values according to the following equations:

$$
\begin{gathered}
\mathrm{DO}_{2}=\mathrm{CaO}_{2} \cdot \dot{\mathrm{Q}} \\
\dot{\mathrm{VO}}_{2}=\left(\mathrm{CaO}_{2}-\mathrm{CvO}_{2}\right) \cdot \dot{\mathrm{Q}} \\
\mathrm{O}_{2} \mathrm{Ex}=\left[\left(\mathrm{CaO}_{2}-\mathrm{CvO}_{2}\right) \cdot\left(\mathrm{CaO}_{2}^{-1}\right)\right] \cdot 100
\end{gathered}
$$

where $\mathrm{CaO}_{2}$ is arterial oxygen content, $\mathrm{CvO}_{2}$ is the superior sagittal sinus oxygen content, and $\mathrm{Q}$ is blood flow to the cerebrum. Because the sagittal sinus drains the cerebral cortex, cerebral white matter, and some deep gray structures, blood flow measured to the cerebrum included these structures. Thus, oxygen metabolism to the total cerebrum is reported. Blood flow was expressed as $\mathrm{L} \cdot \mathrm{min}^{-1} \cdot \mathrm{kg}^{-1}, \mathrm{DO}_{2}$ and $\mathrm{VO}_{2}$ as $\mathrm{mmol} \mathrm{O} \cdot \mathrm{min}^{-1}$. $\mathrm{kg}^{-1}$.

Changes within each group over time were analyzed separately using two-way analysis of variance for repeated measures. If a significant difference was found, the Dunnett's $t$ test was used to compare the means to the baseline and postictal values (25). The unpaired $t$ test was used to compare differences between the groups. When repeated measurements were compared between the groups, the Bonferroni adjustment was used (25). Correlations between cerebral perfusion pressure and total and regional brain blood flow and cerebral oxygen uptake $\left(\mathrm{V}_{2}\right)$ were calculated for the last four postictal blood flow determinations in both groups using a least-squared computerized curve-fitting program. The fit of the data points to the generated curves of the normocarbic postictal and hypocarbic postictal groups were verified statistically by a general linear model to test whether the points of each curve were more adequately described by a polynomial curve or a straight line (26). A value of $p<0.05$ was considered significant unless otherwise indicated. All values were expressed as mean \pm SEM.

\section{RESULTS}

Table 1 summarizes the arterial blood gas, hematocrit, and oxygen content values. Although arterial blood gases were not measured during seizures, both groups showed a similar degree of metabolic acidosis $31 \mathrm{~min}$ after the induction of seizures. After hyperventilation was begun in the hypocarbic group, arterial $\mathrm{pH}$ increased, $\mathrm{PCO}_{2}$ decreased, and $\mathrm{PO}_{2}$ remained unchanged. Thereafter, during graded hemorrhagic hypotension, the normocarbic group became acidotic, whereas the hypocarbic group had normal arterial $\mathrm{pH}$ values because of the lower $\mathrm{PCO}_{2}$ values in this group. During the final determination, the piglets in both groups developed a metabolic acidosis. Changes in arterial hematocrit, oxygen content values, and the volume of blood withdrawn (data not shown) were similar in both groups during each study period.

After bicuculline administration, all animals developed typical tonic-clonic seizures within $1 \mathrm{~min}$ that lasted for 5 to $6 \mathrm{~min}$. The severity and duration of the seizures appeared to be similar in both groups of piglets, as evidenced by equivalent changes in cerebral perfusion and superior sagittal sinus and central venous blood pressures during the clinically apparent seizure activity (Table 2). Cerebral perfusion pressure increased during bicuculline-induced seizures, decreased during the postictal phase, and was equivalently reduced during graded hemorrhagic hypotension in both groups. Central venous and superior sagittal sinus pressures increased during the seizures and decreased during hemorrhagic hypotension in both groups. During the first two measurements (time 0 and $31 \mathrm{~min}$ ), significant differences in total brain blood flow were not observed between the groups. During the postictal phase, after the onset of hyperventilation, total brain blood flow decreased significantly in the hypocarbic piglets. In both groups, total brain blood flow decreased significantly during hemorrhagic hypotension. Total brain blood flow was significantly lower in the normocarbic group during the last hypotensive measurement ( $108 \mathrm{~min})$ compared with the postictal normocarbic period $(55 \mathrm{~min})$, whereas brain blood flow was not significantly lower at this time $(108 \mathrm{~min})$ in the hypocarbic piglets compared with the postictal hypocarbic measurement $(55 \mathrm{~min})$.

Blood flow to the cerebrum (during the last four measurement periods) plotted against cerebral perfusion pressure demonstrated 
Table 1. Arterial blood gas, hematocrit, and oxygen content values during study periods in normocarbic $(n=6)$ and hypocarbic $(n=7)$ piglets*

\begin{tabular}{|c|c|c|c|c|c|c|c|}
\hline \multirow[b]{2}{*}{ Time (min) } & \multirow[t]{2}{*}{ Group } & \multirow{2}{*}{$\frac{\text { Baseline }}{0}$} & \multicolumn{2}{|c|}{$\leftarrow$} & \multicolumn{3}{|c|}{$\begin{array}{l}\text { - Postictal } \longrightarrow \\
\text { - Normocarbia or hypocarbia } \longrightarrow \\
\longrightarrow \text { Hemorrhagic hypotension } \longrightarrow\end{array}$} \\
\hline & & & 31 & 55 & 74 & 92 & 108 \\
\hline \multirow[t]{2}{*}{$\mathrm{pH}$} & $\mathrm{NC}$ & $7.46 \pm 0.01$ & $7.08 \pm 0.11 \dagger$ & $7.12 \pm 0.12 \dagger$ & $7.07 \pm 0.11 \dagger$ & $7.00 \pm 0.11 \dagger$ & $7.02 \pm 0.12 \dagger$ \\
\hline & $\mathrm{HC}$ & $7.44 \pm 0.02$ & $7.06 \pm 0.13 \dagger$ & $7.45 \pm 0.09 \neq$ & $7.50 \pm 0.08 \S$ & $7.48 \pm 0.09 \S$ & $7.18 \pm 0.13+\|$ \\
\hline \multirow{2}{*}{$\mathrm{PCO}_{2}(\mathrm{kPa})$} & $\mathrm{NC}$ & $5.20 \pm 0.13$ & $5.20 \pm 0.13$ & $5.20 \pm 0.13$ & $4.93 \pm 0.13$ & $5.20 \pm 0.27$ & $5.20 \pm 0.13$ \\
\hline & $\mathrm{HC}$ & $5.47 \pm 0.27$ & $5.33 \pm 0.13$ & $3.07 \pm 0.13 \dagger \$ \S$ & $2.67 \pm 0.13+\S$ & $2.80 \pm 0.13+\S$ & $3.07 \pm 0.13+\S$ \\
\hline $\mathrm{PO}_{2}(\mathrm{kPa})$ & $\mathrm{HC}$ & $10.40 \pm 0.53$ & $11.07 \pm 0.27$ & $11.73 \pm 0.67$ & $12.53 \pm 0.80 \dagger$ & $12.80 \pm 0.80 \dagger$ & $13.33 \pm 1.07 \dagger$ \\
\hline \multirow[t]{2}{*}{ Hct } & $\mathrm{NC}$ & $0.30 \pm 0.02$ & $0.31 \pm 0.02$ & $0.30 \pm 0.02$ & $0.27 \pm 0.01$ & $0.23 \pm 0.01 \dagger \|$ & $0.20 \pm 0.01 \dagger \|$ \\
\hline & $\mathrm{HC}$ & $0.27 \pm 0.02$ & $0.28 \pm 0.02$ & $0.27 \pm 0.02$ & $0.24 \pm 0.02 \dagger \|$ & $0.20 \pm 0.02 \dagger \|$ & $0.17 \pm 0.02 \dagger \|$ \\
\hline \multirow[t]{2}{*}{$\mathrm{CaO}_{2}\left(\mathrm{mmol} \cdot \mathrm{L}^{-1}\right)$} & $\mathrm{NC}$ & $4.73 \pm 0.36$ & $4.55 \pm 0.27$ & $4.59 \pm 0.27$ & $3.79 \pm 0.27 \dagger \|$ & $3.39 \pm 0.14 \uparrow \|$ & $2.85 \pm 0.18+\|$ \\
\hline & $\mathrm{HC}$ & $4.01 \pm 0.22$ & $3.70 \pm 0.18$ & $4.10 \pm 0.27$ & $3.75 \pm 0.22 \|$ & $3.26 \pm 0.27 \dagger \|$ & $2.63 \pm 0.31 \dagger \|$ \\
\hline
\end{tabular}

${ }^{*} \mathrm{NC}$, normocarbic; $\mathrm{HC}$, hypocarbic; $\mathrm{Hct}$, hematocrit; $\mathrm{CaO}_{2}$, arterial oxygen content.

$\dagger p<0.05$ vs baseline.

$\ddagger p<0.05$ vs postictal normocarbia study period (time $=31 \mathrm{~min}$ ).

$\S p<0.01$ vs normocarbic group.

$\| p<0.05$ vs postictal normocarbia or hypocarbia study period (time $=55 \mathrm{~min}$ ).

Table 2. Hemodynamic variables in normocarbic $(n=6)$ and hypocarbic $(n=7)$ piglets*

\begin{tabular}{|c|c|c|c|c|c|c|c|c|}
\hline \multirow[b]{2}{*}{ Time (min) } & \multirow[t]{2}{*}{ Group } & \multirow{2}{*}{$\begin{array}{c}\text { Baseline } \\
0\end{array}$} & \multirow[t]{2}{*}{ Seizure } & \multicolumn{5}{|c|}{$\longleftrightarrow \stackrel{\text { Postictal } \longrightarrow \text { Normocarbia or hypocarbia } \longrightarrow \text { Hemorthagic hypotension } \longrightarrow}{\longleftrightarrow}$} \\
\hline & & & & 31 & 55 & 74 & 92 & 108 \\
\hline \multirow{2}{*}{$\begin{array}{l}\text { Cerebral perfusion } \\
\text { pressure }(\mathrm{kPa})\end{array}$} & $\mathrm{NC}$ & $8.40 \pm 0.28$ & $11.3 \pm 0.72 \dagger$ & $10.67 \pm 1.17 \dagger$ & $9.97 \pm 0.75$ & $7.42 \pm 0.29 \ddagger$ & $6.01 \pm 0.20 \dagger \ddagger$ & $4.65 \pm 0.97 \dagger$ \\
\hline & $\mathrm{HC}$ & $9.08 \pm 0.53$ & $10.5 \pm 0.8$ & $10.52 \pm 0.33 \dagger$ & $8.71 \pm 0.56 \S$ & $6.87 \pm 0.09+\ddagger$ & $5.80 \pm 0.23+t$ & $4.33 \pm 0.28+t$ \\
\hline \multirow{2}{*}{$\begin{array}{l}\text { Heart rate } \\
\quad\left(\text { beats } \cdot \min ^{-1}\right)\end{array}$} & $\mathrm{NC}$ & $187 \pm 8$ & ND & $181 \pm 7$ & $197 \pm 13$ & $261 \pm 13 \dagger$ & $243 \pm 21 \dagger$ & $232 \pm 16 \dagger$ \\
\hline & $\mathrm{HC}$ & $225 \pm 16$ & ND & $202 \pm 23$ & $256 \pm 11 \S$ & $243 \pm 18$ & $214 \pm 16$ & $191 \pm 19 \ddagger$ \\
\hline \multirow{2}{*}{$\begin{array}{l}\text { Central venous } \\
\text { pressure }(\mathrm{kPa})\end{array}$} & $\mathrm{NC}$ & $-0.09 \pm 0.11$ & $2.17 \pm 0.37 \dagger$ & $-0.04 \pm 0.13$ & $-0.07 \pm 0.19$ & $-0.40 \pm 0.17 \dagger \ddagger$ & $-0.43 \pm 0.17 \dagger t$ & $-0.56 \pm 0.15$ \\
\hline & $\mathrm{HC}$ & $0.16 \pm 0.03 \|$ & $2.20 \pm 0.41 \dagger$ & $0.17 \pm 0.13$ & $0.21 \pm 0.10$ & $-0.16 \pm 0.01 \|$ & $-0.01 \pm 0.17 \ddagger$ & $-0.08 \pm 0.11+\$ \|$ \\
\hline \multirow{2}{*}{$\begin{array}{l}\text { Sagittal sinus } \\
\text { pressure }(\mathrm{kPa})\end{array}$} & $\mathrm{NC}$ & $0.17 \pm 0.11$ & $5.95 \pm 0.62 \dagger$ & $0.17 \pm 0.12$ & $0.00 \pm 0.15$ & $-0.33 \pm 0.12 \dagger \ddagger$ & $-0.25 \pm 0.15 \dagger \ddagger$ & $-0.31 \pm 0.12 \dagger \ddagger$ \\
\hline & $\mathrm{HC}$ & $0.45 \pm 0.13$ & $6.00 \pm 1.20 \dagger$ & $0.21 \pm 0.11$ & $0.25 \pm 0.13$ & $0.20 \pm 0.09 \|$ & $0.05 \pm 0.12 \dagger \ddagger$ & $-0.04 \pm 0.15 \dagger \ddagger$ \\
\hline \multirow{2}{*}{$\begin{array}{l}\text { Total brain } \\
\text { blood flow } \\
\left(\mathrm{L} \cdot \mathrm{min}^{-1} \cdot \mathrm{kg}^{-1}\right)\end{array}$} & $\mathrm{NC}$ & $0.95 \pm 0.09$ & ND & $0.98 \pm 0.21$ & $0.82 \pm 0.11$ & $0.69 \pm 0.08$ & $0.63 \pm 0.06$ & $0.51 \pm 0.12 \dagger \ddagger$ \\
\hline & $\mathrm{HC}$ & $0.98 \pm 0.09$ & ND & $0.86 \pm 0.10$ & $0.63 \pm 0.07 \dagger$ & $0.70 \pm 0.11$ & $0.60 \pm 0.07 \dagger$ & $0.43 \pm 0.11 \dagger$ \\
\hline
\end{tabular}

$* \mathrm{NC}$, normocarbic; $\mathrm{HC}$, hypocarbic; ND, not determined.

$+p<0.05$ vs baseline.

$\ddagger p<0.05$ vs postictal normocarbia or hypocarbia study period (time $=55 \mathrm{~min}$ ).

$\S p<0.05 v s$ postictal normocarbia study period (time $=31 \mathrm{~min}$ ).

$\| p<0.01$ vs normocarbic group.

a direct linear relationship $(y=0.08 x+0.05, r=0.67, n=28$, $p<0.001)$ in the normocarbic group after seizures, whereas in the hypocarbic piglets it showed a polynomial relationship ( $y=$ $0.34 x-0.02 x^{2}-0.71, r=0.60, n=24, p<0.001$, Fig. 1). The general linear model (26) used to statistically verify that the points of each curve were more adequately described by a polynomial curve or a straight line demonstrated that the points in the hypocarbic group were best described by a polynomial curve fit, $F=4.63, p<0.05$. Inspection of Figure 1 suggests that one point in the normocarbic group had a value for cerebral perfusion pressure and blood flow that exceeded the other values for this group. Regression analysis repeated without this outlying value demonstrated that the linear function remained appropriate $(y$ $=0.07 x+0.13, r=0.53, n=27, p<0.01$ ). Similar patterns of change were also observed for total brain blood flow $(y=0.08 x$ $+0.12, r=0.68, n=28, p<0.001$, and $y=0.33 x-0.03 x^{2}-$ $0.62, r=0.55, n=24, p<0.001$ in the normocarbic and hypocarbic piglets, respectively). Similarly, the curve for the total brain blood flow and cerebral perfusion pressure in the hypocarbic group was best described by a polynomial curve fit, $F=4.39$, $p<0.05$. In the normocarbic postictal piglets, the relationship between cerebellar blood flow and cerebral perfusion pressure was described by a polynomial curve fit $\left(y=0.33 x-0.02 x^{2}-\right.$ $0.52, r=0.064, n=28, p<0.001$; polynomial curve fit: $F=$

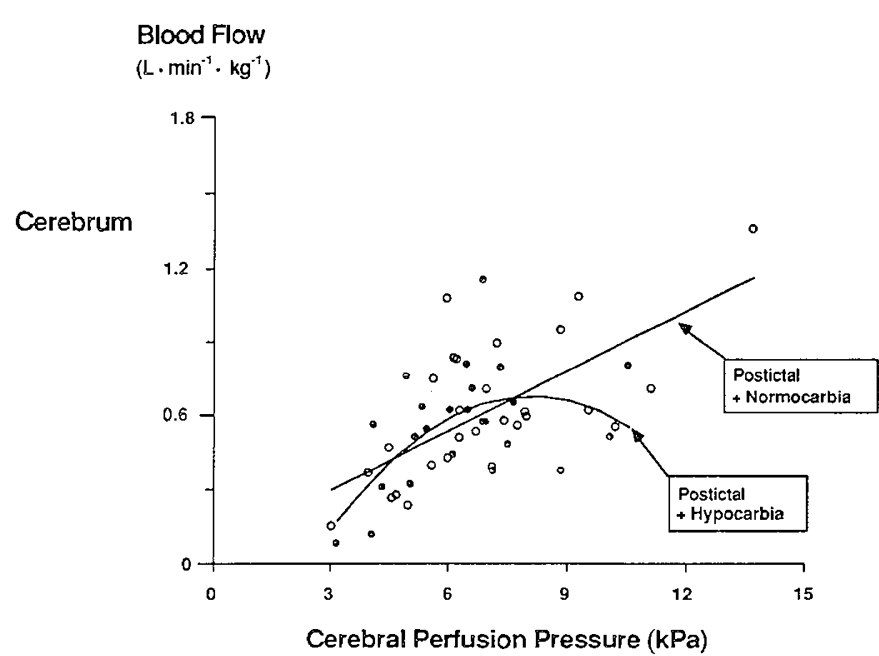

Fig. 1. A scattergram of cerebral blood flow plotted against perfusion pressure. The postictal normocarbic group is shown by open circles and the hypocarbic group by closed circles. 
$5.71, p<0.05)$ and in the postictal hypocarbic piglets no significant correlation was found between these variables $(r=0.35, n$ $=24, p=$ NS, Fig. 2). The relationship between blood flow to the brainstem and cerebral perfusion pressure was not significant in either the normocarbic ( $r=0.34, n=28, p=\mathrm{NS})$ or hypocarbic ( $r=0.21, n=24, p=\mathrm{NS})$ group.

Table 3 summarizes the changes in cerebral oxygen metabolism during the studies in the normocarbic and hypocarbic piglets. Cerebral oxygen delivery decreased during the postictal period in the hypocarbic piglets and in both groups during hemorrhagic hypotension. Cerebral oxygen extraction increased during the postictal period (time $=31 \mathrm{~min}$ ) in both groups, in the hypocarbic group during the postictal hypocarbic period (time $=55 \mathrm{~min}$ ), and in both groups during hemorrhagic hypotension. Cerebral oxygen uptake was unchanged in both groups after seizures and reduced during the final hemorrhagic hypotensive determination. The pattern of cerebral oxygen uptake (during the last four measurement periods) plotted against perfusion pressure demonstrated a direct linear relationship in the normocarbic group $(y=0.23 x-0.02, r=0.72, n=28, p<0.001)$, whereas in the hypocarbic group it showed a polynomial relationship ( $y=1.19 x-0.07 x^{2}-2.84, r=0.68, n=24, p<$ 0.001 ; polynomial curve fit: $F=8.38, p<0.01$, Fig. 3 ).

\section{DISCUSSION}

We have previously shown that, during the postictal state of bicuculline-induced seizures, cerebral blood flow autoregulation is impaired (13). In the current study, we tested the hypothesis that the loss of cerebral blood flow autoregulation is a result of increased perivascular carbon dioxide and hydrogen ion concentration and that normalization of these two elements by hyperventilation would restore autoregulation of cerebral blood flow. Our current results confirm the previous findings that cerebral blood flow autoregulation is indeed impaired in the postictal

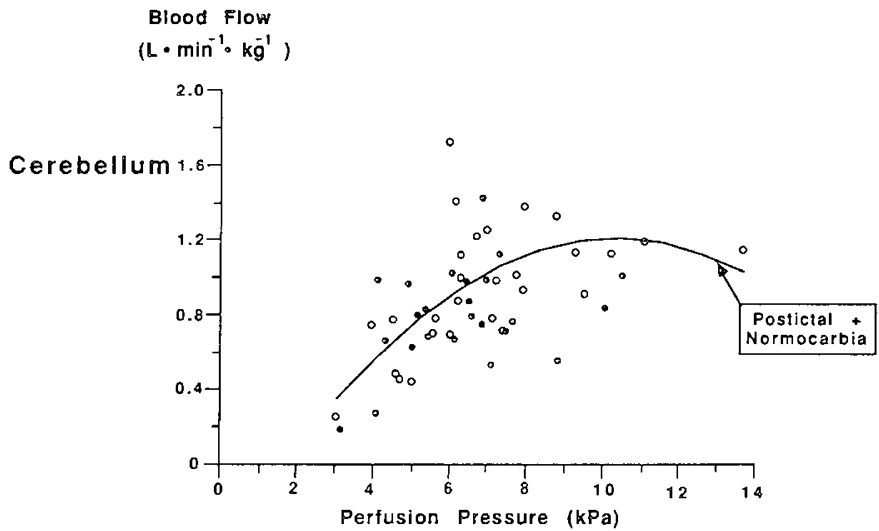

Fig. 2. A scattergram of cerebellar blood flow plotted against perfusion pressure. Group legends are as for Figure 1. state (13). Furthermore, we have shown that a reduction in the carbon dioxide and hydrogen ion concentrations of the arterial blood via hyperventilation does restore autoregulation of cerebral blood flow during the postictal state.

Our speculations regarding these findings are as follow. Bicuculline-induced seizures result in cerebral vasodilation in response to increased perivascular carbon dioxide production and hydrogen ion concentrations $(15,19)$. In response to a seizurerelated elevation in brain metabolism, increased perivascular hydrogen ion and carbon dioxide concentrations may persist, resulting in continued vasodilation, potentially accounting for the loss of cerebral blood flow autoregulation in the postictal normocarbic piglets. However, after seizures (time $31 \mathrm{~min}$ ), cerebral blood flow was not increased, suggesting that vasodilation was not present at this time and thus cannot account for the loss of autoregulation in the postictal period. On the other hand, our findings are consistent with previous reports of a relatively rapid brain $\mathrm{pH}$ buffering process after ischemia (27, 28 ). Therefore, although postictal vasodilation was not evident (time $31 \mathrm{~min}$ ), the seizures rendered the cerebral vasculature sensitive to the loss of autoregulation during the postictal state, when hypotension was induced. Thus, it remains possible that perivascular carbon dioxide and hydrogen ion are produced more readily in response to hypotension in the postictal than in the normal state, accounting for the lack of vasoconstriction when hypotension was induced and the consequent pressure-passive relationship between cerebral blood flow and perfusion pressure. These contentions are supported by our findings in the hypocarbic postictal group. Hyperventilation was associated with a reduction in arterial carbon dioxide and an increase in $\mathrm{pH}$. $\mathrm{Al}$ though we did not measure cerebral perivascular carbon dioxide and hydrogen ion concentration directly, we speculate that the significant reduction in arterial carbon dioxide concentration might have resulted in a washout phenomenon, significantly lowering the perivascular carbon dioxide and hydrogen ion concentrations $(14,15,19)$ and restoring the ability of the cerebral vasculature to vasoconstrict to reductions in perfusion pressure in the postictal state. Thus, the presence of cerebral autoregulation in the hypocarbic group, despite the reduction in perfusion pressure, suggests that the loss of autoregulation in the postictal state in the normocarbic group depends in part upon the magnitude of the perivascular carbon dioxide-mediated cerebral vasodilation.

Several other metabolic (29) and vasoactive compounds (30, 31) critical to cerebral blood flow autoregulation and seizurerelated cerebral hyperperfusion may also participate in the loss of autoregulation in the postictal state, including potassium released during neural firing, prostanoids (30), and adenosine (31). However, we did not evaluate the importance of these components with respect to the postictal regulation of cerebral blood flow and cannot comment upon the relative contributions of each of these factors to the loss of cerebral autoregulation in the postictal state.

Table 3. Cerebral metabolic changes in normocarbic $(n=6)$ and hypocarbic $(n=7)$ piglets*

\begin{tabular}{|c|c|c|c|c|c|c|c|}
\hline \multirow[b]{2}{*}{ Time (min) } & \multirow[t]{2}{*}{ Group } & \multirow{2}{*}{ Baseline } & \multicolumn{5}{|c|}{$\longleftrightarrow$ Postictal $\longrightarrow$ Normocarbia or hypocarbia $\longrightarrow$} \\
\hline & & & 31 & 55 & 74 & 92 & 108 \\
\hline \multirow[t]{2}{*}{$\mathrm{Do}_{2}\left(\mathrm{mmol} \mathrm{O} \cdot \mathrm{min}^{-1} \cdot \mathrm{kg}^{-1}\right)$} & $\mathrm{NC}$ & $4.42 \pm 0.45$ & $4.28 \pm 1.03$ & $3.57 \pm 0.67$ & $2.50 \pm 0.40 \dagger \ddagger$ & $1.87 \pm 0.27 \dagger \ddagger$ & $1.34 \pm 0.36+\ddagger$ \\
\hline & $\mathrm{HC}$ & $3.84 \pm 0.27$ & $2.81 \pm 0.27$ & $2.45 \pm 0.31+\S$ & $2.36 \pm 0.22 \dagger$ & $1.78 \pm 0.27 \dagger \ddagger$ & $1.16 \pm 0.40 \dagger \ddagger$ \\
\hline \multirow[t]{2}{*}{$\mathrm{O}_{2} \mathrm{Ext}$} & $\mathrm{NC}$ & $0.55 \pm 0.02$ & $0.67 \pm 0.03 \dagger$ & $0.60 \pm 0.05$ & $0.74 \pm 0.02 \dagger$ & $0.76 \pm 0.03 \dagger \ddagger$ & $0.73 \pm 0.02 \dagger \ddagger$ \\
\hline & $\mathrm{HC}$ & $0.56 \pm 0.02$ & $0.72 \pm 0.03 \dagger$ & $0.78 \pm 0.02+\|$ & $0.79 \pm 0.02 \dagger$ & $0.80 \pm 0.02 \dagger$ & $0.81 \pm 0.02 \dagger$ \\
\hline \multirow[t]{2}{*}{$\dot{\mathrm{V}}_{2}\left(\mathrm{mmol} \mathrm{O} \mathrm{O}_{2} \cdot \mathrm{min}^{-1} \cdot \mathrm{kg}^{-1}\right)$} & $\mathrm{NC}$ & $2.41 \pm 0.18$ & $2.94 \pm 0.71$ & $2.05 \pm 0.22$ & $1.83 \pm 0.22$ & $1.38 \pm 0.18$ & $1.03 \pm 0.22 \dagger \ddagger$ \\
\hline & $\mathrm{HC}$ & $2.19 \pm 0.18$ & $2.01 \pm 0.09$ & $1.87 \pm 0.22$ & $1.87 \pm 0.13$ & $1.38 \pm 0.22$ & $0.94 \pm 0.31 \dagger \ddagger$ \\
\hline
\end{tabular}

* $\mathrm{NC}$, normocarbic; $\mathrm{HC}$, hypocarbic; $\mathrm{Do}_{2}$, cerebral oxygen delivery; $\mathrm{O}_{2}$ Ext, cerebral oxygen extraction; $\mathrm{V}_{2}$, cerebral oxygen uptake.

$+p<0.05$ vs baseline.

$\ddagger p<0.05$ vs postictal normocarbia or hypocarbia study period (time $=55 \mathrm{~min}$ ).

$\S p<0.01$ vs normocarbic group.

$\| p<0.05 v s$ postictal normocarbia study period $($ time $=31 \mathrm{~min})$. 


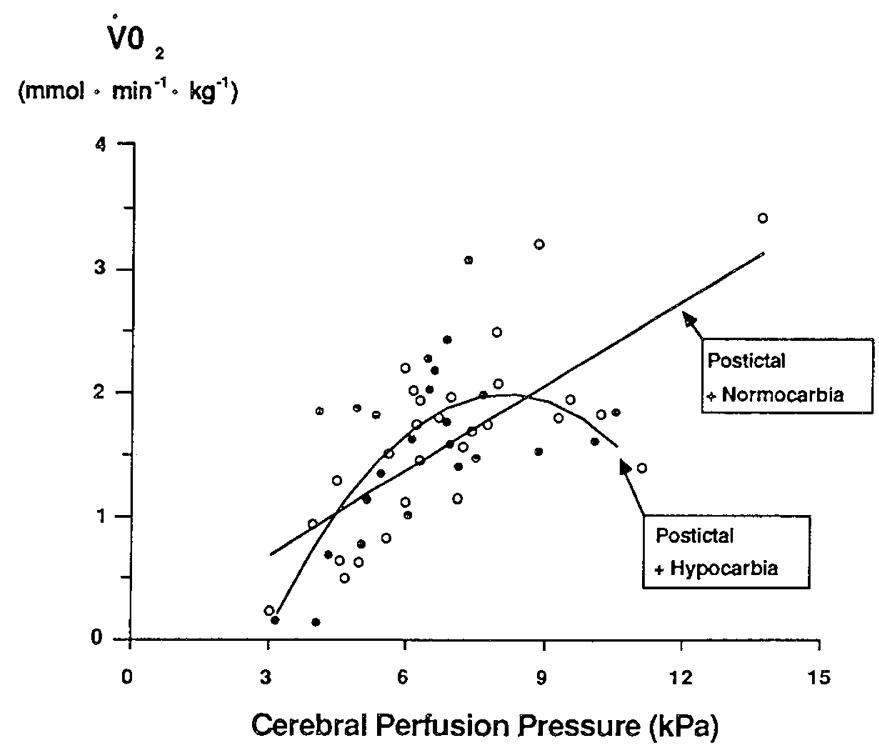

Fig. 3. Cerebral oxygen uptake $\left(\mathrm{V}_{2}\right)$ plotted against perfusion pressure. Group legends are as for Figure 1.

The loss of autoregulation of brain blood flow during the postictal period may also be explained by the seizure-mediated increase in perfusion pressure. The seizure-related increases in perfusion pressure and hypotension-induced decreases in pressure were of similar magnitudes in both groups. Brubakk et al. (7) demonstrated that cerebral vasodilation persists for $30 \mathrm{~min}$ after pharmacologically induced systemic hypertension. However, the equivalent increase in cerebral perfusion pressure observed in both groups of piglets and loss of autoregulation only in the normocarbic piglets suggest that hypertension is not a likely mechanism for the loss of autoregulation in the normocarbic postictal piglets.

The relative resistance of the cerebellum and brainstem to reductions in blood flow during hemorrhagic hypotension in both groups confirms previous findings suggesting a greater resistance of the more caudal brain structures to a loss of autoregulation $(2,3,7)$. Our present results suggest that the cerebellum and brain stem are also more resistant to a loss of autoregulation after seizures. Alternatively, it is possible that these subcortical structures were not affected by seizures.

In our study, cerebral oxygen uptake was not increased during the first postictal determination (time $31 \mathrm{~min}$ ), possibly because of the time lapse between the onset of seizures and the postictal measurements. The pattern of change in cerebral oxygen uptake with changes in perfusion pressure was similar to that of cerebral blood flow in the normocarbic and hypocarbic groups, such that at the lowest perfusion pressures (time $108 \mathrm{~min}$ ) cerebral metabolic rate for oxygen was compromised. This $50 \%$ decrease in cerebral oxygen availability may have affected blood flow at the lowest perfusion pressures in both groups. Because cerebral oxygen uptake was maintained until cerebral perfusion pressure was $4.4 \mathrm{kPa}$ in the hypocarbic group, the magnitude and duration of hypocarbia, per se, during the postictal period did not result in tissue hypoxia. Cerebral oxygen uptake was maintained because of increments in oxygen extraction after seizures, hyperventilation, and hemorrhagic hypotension, until the lowest cerebral perfusion pressures were reached.

In summary, we have confirmed our previously reported impairment of cerebral blood flow autoregulation in newborn piglets after bicuculline-induced seizures during the postictal state. We also showed that hyperventilation with the concomitant reduction in arterial carbon dioxide and hydrogen ion concentration restores cerebral blood flow autoregulation, which strongly suggests that changes in perivascular carbon dioxide and hydrogen ion are in part responsible for the loss of cerebral vascular autoregulation during the postictal state.

Acknowledgments. The authors thank Caroline Mueller, Armando Signore, and Yvonne Mark for their skillful technical assistance and John C. Pezzullo, Ph.D., for assistance with the statistical analysis and the development of the computer-assisted curve-fitting programs.

\section{REFERENCES}

1. Hernandez MJ 1980 Autoregulation of cerebral blood flow in the newborn dogs. Brain Res 184:199-202

2. Laptook AR, Stonestreet BS, Oh W 1983 Brain blood flow and $\mathrm{O}_{2}$ delivery during hemorrhagic hypotension in the piglet. Pediatr Res 17:77-80

3. Laptook A, Stonestreet BS, Oh W 1982 Autoregulation of brain blood flow reduction during hypotension. Early Hum Dev 6:99-107

4. Mchedlishvili GI, Mitaguaria NP, Ormotsadze LG 1973 Vascular mechanism controlling a constant blood supply to the brain (autoregulation). Stroke 4:742-750

5. Pasternak JF, Groothuis DR 1985 Autoregulation of cerebral blood flow in the newborn beagle puppy. Biol Neonate 48:100-109

6. Ashwal S, Dale PS, Longo LD 1984 Regional cerebral blood flow: studies in the fetal lamb during hypoxia, hypercapnia, acidosis and hypotension. Pe diatr Res 18:1309-1316

7. Brubakk A-M, Bratlid D, Oh W, Yao AC, Stonestreet BS 1984 Atropin prevents pressure-passive increases in brain blood flow during hypertension. Pediatr Res 18:1121-1126

8. Klein M, Sugerman M 1982 Seizures, a neglected pathogenesis in neonatal intraventricular hemorrhage. Pediatr Res 15:667A(abstr)

9. Lou HC, Lassen NA, Friis-Hansen B 1979 Impaired autoregulation of cerebral blood flow in the distressed newborn infant. J Pediatr 94:118-121

10. Stonestreet BS, Goldstein M, Piva D, Barefield E 1986 Autoregulation of brain blood flow during hypercarbia in piglets. Pediatr Res 20:468A(abstr)

11. Tweed A, Cote J, Lou H, Gregroy G, Wade J 1986 Impairment of cerebra blood flow autoregulation in the newborn lamb by hypoxia. Pediatr Res $20 \cdot 516-519$

12. Clozel M, Daval JL, Monin P, Dubruc C, Morselli PL, Vert P 1985 Regiona cerebral blood flow during bicuculline-induced seizures in the newborn piglet: effect of phenobarbital. Dev Pharmacol Ther 8:189-199

13. Hascoet JM, Monin P, Vert P 1988 Loss of cerebral blood flow autoregulation (CBF.AR) in the postictal period. Epilepsia 29:743-747

14. Kuschinsky W, Wahl M, Bosse O, Thuran K 1972 Perivascular potassium and $\mathrm{pH}$ as determinants of local pial arterial diameters in cats. A microapplication study. Circ Res 31:240-247

15. Kuschinsky W, Wahl M 1979 Perivascular $\mathrm{pH}$ and pial arterial diameter during bicuculline-induced seizures in cats. Pflugers Arch 382:81-85

16. Lou HC, Friis-Hansen B 1979 Arterial blood pressure elevations during motor activity and epileptic seizures in the newborn. Acta Pediatr Scand 68:803806

17. Meldrum BS, Horton RW 1973 Physiology of status epilepticus in primates Arch Neurol 28:1-9

18. Meldrum B 1978 Physiological changes during prolonged seizures and epileptic brain damage. Neuropadiatrie 9:203-212

19. Leniger-Follert E 1984 Mechanisms of regulation of cerebral microflow during bicuculline-induced seizures in anaesthetized cats. J Cereb Blood Flow Metab $4 \cdot 150-165$

20. Hansen NB, Brubakk AM, Bratlid D, Oh W, Stonestreet BS 1984 The effect of variations in $\mathrm{PaCO}_{2}$ on brain blood flow and cardiac output in the newborn piglet. Pediatr Res 18:1132-1136

21. Orr JA, Desoigne RC, Wagerle LC, Fraser DB 1983 Regional cerebral blood flow during hypercapnia in anesthetized rabbit. Stroke 14:802-807

22. Laptook AR, Stonestreet BS, Oh W 1983 The effect of carotid artery ligation on brain blood flow in newborn piglet. Brain Res 276:51-54

23. Heymann MA, Payne BD, Hoffman JIF, Rudolph AM 1977 Blood flow measurements with radionuclide-labelled particles. Prog Cardiovase Di 20:35-79

24. Mayfield SR, Stonestreet BS, Brubakk AM, Shaul PW, Oh W 1986 Regiona blood flow in newborn piglets during environmental cold stress. Am J Physiol 251:G308-G313

25. Wallenstein S, Zucker CL, Fleiss JL 1980 Some statistical methods useful in circulation research. Circ Res 47:1-9

26. Searle SR 1971 Some other analyses. In: Linear Models. John Wiley \& Sons, New York, pp 355-361

27. Nemoto E, Frinak S 1981 Brain tissue $\mathrm{pH}$ after global brain ischemia and barbiturate loading in rats. Stroke 12:77-82

28. Kraig RP, Pulsinelli WA, Plum F 1985 Hydrogen ion buffering during complete brain ischemia. Brain Res 342:281-290

29. Fox PT, Raichle ME, Min Tun Ma, Dence C 1988 Nonoxidative glucose consumption during focal physiologic neural activity. Science 241:462-464

30. Busija DW, Leffler CW 1989 Role of prostanoids in cerebrovascular response during seizures in piglets. Am J Physiol 256:H120-H125

31. Schrader J, Wahl M, Kuschinsky W 1980 Increase of adenosine content in cerebral cortex of the cat during bicuculline-induced seizures. Pflugers Arch $387: 245-251$ 